\title{
Insulin-induced localized lipoatrophy preceded by shingles (herpes zoster): a case report
}

\author{
Ernst A Chantelau ${ }^{1 *}$, Ruth Prätor ${ }^{2}$ and Jörg Prätor ${ }^{2}$
}

\begin{abstract}
Introduction: Localized involutional lipoatrophy of subcutaneous adipose tissue may develop due to subcutaneous injection of pharmaceutical preparations. The pathogenesis of this adverse drug reaction is unknown. The progression of localized involutional lipoatrophy ceases and occasionally it resolves after withdrawing the inducing agent. In case of localized involutional lipoatrophy due to subcutaneous insulin therapy, low-dose systemic corticosteroids may be curative despite ongoing insulin administration.

Case presentation: We report a recurrence of insulin-induced localized involutional lipoatrophy at the abdominal wall in a 57-year-old Caucasian woman with type-1 diabetes on continuous subcutaneous insulin infusion. The first episode of insulin-induced localized involutional lipoatrophy two years previously had been cured by oral prednisone. The recurrence was treated immediately with $10 \mathrm{mg}$ prednisone once daily for five months, and was cured thereafter. The insulin analog preparation (Humalog ${ }^{\mathrm{TM}}$ ) and the insulin pump equipment (Accu-Chek Spirit ${ }^{\mathrm{TM}}$ ) applied were the same during both episodes. Both episodes were preceded by a temporary disturbance of the immune balance (the first episode by vaccination, the second episode through shingles).

Conclusions: This case confirms that insulin-induced localized involutional lipoatrophy in type-1 diabetes can occur again, and can be cured by systemic corticosteroids. We suggest that temporary disturbance of the immune balance may trigger this transitory idiosyncratic reaction in a susceptible individual.
\end{abstract}

\section{Introduction}

Localized involutional lipoatrophy (LIL) of subcutaneous adipose tissue is a rare condition, characterized by reduction of fat cells in size, and, occasionally, in number. The fat tissue involution develops without symptomatic inflammation, although histopathology of incipient cases may reveal few inflammatory cells among the atrophic fat tissue. Muscle tissue is never involved.

Lopez et al. [1] have obtained biopsies of lipoatrophies in three patients shortly after the last insulin injection; histopathology showed some lymphocytic, eosinophilic, and mast cell infiltration. However, direct immunofluorescence for immunoglobulin G (IgG), for immunoglobulin A ( $\operatorname{IgA}$ ), immunoglobulin $M$ (IgM), complement component 3 (C3) and fibrin could not be demonstrated [1], in line with other authors [2]. Adipose tissue was atrophied, with focal fibrosis [1]. Adipocytes were shrunk and reduced in number,

\footnotetext{
* Correspondence: chantelau@gmx.de

${ }^{1}$ Practice of Endocrinology and Diabetology, PD Dr. Kimmerle, Aachener Strasse 196, 40223 Düsseldorf, Germany

Full list of author information is available at the end of the article
}

consistent with previous reports [3-5]. Milan et al. [6] provided ultrastructural analyses on chronic lipoatrophies, having existed for eight months to six years (median 26 months) in three patients using Humalog ${ }^{\mathrm{Tm}}$. They showed fat cell atrophy, deposition of amyloid, and numerous perivascular preadipocytes. Quantitative polymerase chain reaction revealed a reduction in adipocyte-specific messenger ribonucleic acid (mRNA) (perilipin, adiponectin, fatty acid-binding protein 4 , peroxisome proliferator-activated receptor gamma 2), whereas mRNA of adipocyte enhancerbinding protein 1 was enhanced, and of leptin was reduced to zero [6]. There was no evidence of inflammation. Rather, the histopathologic pattern was like that of fat tissue undergoing starvation, except for the amyloid deposition, that is conglomerates of denaturated exogenous insulin or insulin analog [7].

The etiopathogenesis of the LIL is unknown; it is associated with various immunological disorders (for example type-1 diabetes mellitus, immunogenic thyreopathies) and has a female preponderance. LIL is probably idiopathic, but develops predominantly after local mechanical trauma 
or subcutaneous administration of pharmaceuticals (for example insulin, antibiotics, vaccines, corticosteroids, growth hormone). The drug-induced type of LIL stops spreading after withdrawal of the agent. In children, insulin-induced LIL may resolve spontaneously after changing the insulin brand [8].

We have recently reported on a patient with incipient LIL induced by external insulin pump therapy with Humalog $^{\text {TM }}$ [5]. Within 10 months of low-dose oral prednisone treatment, the LIL resolved completely. We now report another episode of LIL in the same patient, at an insulin infusion site close to a previously lipoatrophic area.

\section{Case presentation}

Our patient is a 57-year-old Caucasian woman born in 1956 and diagnosed with type-1 diabetes mellitus in 1969. At the time of writing this report, in March 2014, she is still free from significant diabetic retinopathy, nephropathy, and neuropathy. She has been treated with an insulin pump since 1984, and has been using a U-100 analog insulin lispro (Humalog ${ }^{\mathrm{Ts}}$, Eli Lilly Deutschland, Bad Homburg, Germany) since 2004. The equipment applied from 2008 onward comprised an Accu-Chek Spirit ${ }^{\mathrm{TM}}$ insulin pump and Accu-Chek FlexLink ${ }^{\text {TM }}$ infusion sets with $8 \mathrm{~mm}$ steel cannula (all from Roche Diabetes Care, Burgdorf, Switzerland). The cannula part of the infusion set was changed every two days, and the tubing $(60 \mathrm{~cm}$ long) was changed every 10 days, together with the insulin reservoir inside the pump. The dose of Humalog ${ }^{\mathrm{TM}}$ was around 25 to 30 units/day. Apart from Humalog ${ }^{\mathrm{TM}}$, her current medication consists of levothyroxine $125 \mu \mathrm{g}$ once daily because of immunogenic thyroid atrophy. Her most recent glycated hemoglobin (HbA1c) test result (normal range 4 to 6 percent of total hemoglobin) was 6.3 percent, and her body mass index was 23 to $24 \mathrm{~kg} / \mathrm{m}^{2}$.
Following a hepatitis vaccination with Twinrix ${ }^{\text {TM }}$ (GlaxoSmithKline Dresden, Germany), in 2007 and 2008, our patient had experienced a first episode of LIL at the Humalog $^{\mathrm{TM}}$ infusion sites on both sides of the umbilicus. The lipoatrophic defects were cured by low-dose oral prednisone therapy from 2009 to 2010, as we published in 2011 [5]. After a prolonged cold between December 2011 and January 2012, herpes zoster (shingles) broke out at the left thoracolumbar region ( $\mathrm{T} 10$ dermatome), and healed uneventfully in February 2012. Shortly thereafter, in March 2012, a solitary spot of subcutaneous fat atrophy was noticed at one catheter insertion site on the abdominal wall left of the umbilicus (Figure 1), and was diagnosed as LIL recurrence.

Laboratory tests were limited to determinations of varicella-zoster virus (VZV) IgG-antibody titer (3230mIU/ $\mathrm{ml}$; enzyme-linked immunosorbent assay (ELISA), nor$\mathrm{mal}<149 \mathrm{mIU} / \mathrm{ml}), \mathrm{VZV}$ IgM negative; herpes simplex virus IgG-antibody titer (7 IU; normal <0.9 IU), human leukocyte antigen (HLA)-Cw7 (positive), HLA-Cw6 (negative), HLAB27 (negative), HLA-DR4 (negative), and HLA-DRB1*03 allele (positive). Other markers of autoimmune diseases (like antinuclear antibodies (ANA), antinuclear cytoplasmatic antibodies (ANCA)) had previously been found negative [5]. Because of the limited information gained from biopsies during the first episode of LIL [5], biopsies were not repeated on this occasion.

It was decided to carry on with the insulin preparation $\left(\right.$ Humalog $^{\mathrm{TM}}$ ) and the pump equipment unchanged, at variance to the first LIL episode. Oral prednisone therapy was initiated by mid-April 2012, when the atrophic area was still relatively small (approximately $3 \mathrm{~cm}$ in diameter, see Figure 1). The starting dose was $10 \mathrm{mg} /$ day, which was reduced deliberately to $5 \mathrm{mg} /$ day after nine weeks (the end of June 2012), and discontinued by the

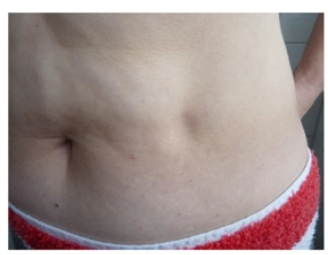

15.4.2012

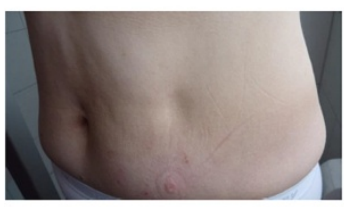

21.8.2012

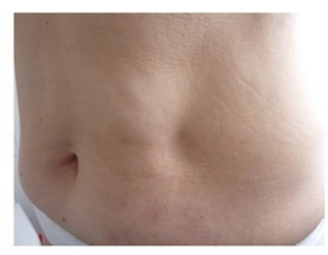

9.6 .2012

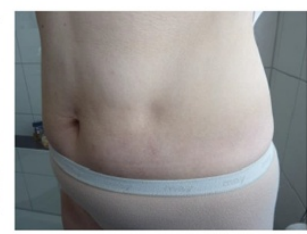

2.9 .2012

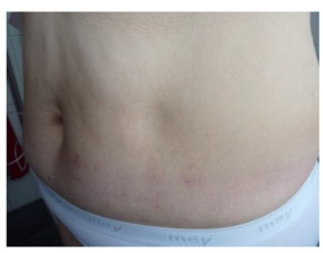

15.7.2012

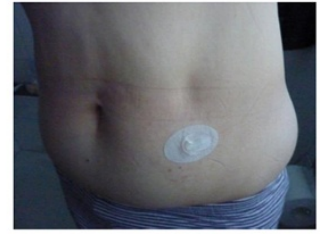

2.12.2012.

Figure 1 Development of localized involutional lipoatrophy at the insulin infusion site before (15 April 2012) and during treatment with oral prednisone (10 mg/day from 15 April 2012 to 26 June 2012, 5 mg/day until 21 August 2012). No prednisone from 22 August 2012 until December 2012. 
end of August 2012. The reasons for discontinuation were intolerable emotional disturbances and blood glucose instability, attributed to prednisone. At that time point, the lipoatrophy had improved (see Figure 1) but the excavation was not entirely refilled. There were no new lipoatrophic sites. By the end of December 2012, prednisone $10 \mathrm{mg}$ /day was resumed in order to improve the remaining lipoatrophy (Figure 2), and was tapered off by the end of March 2013, because the lipoatrophy was almost cured. The total duration of $10 \mathrm{mg}$ prednisone daily was 20 weeks (five months). In March 2014, the LIL was still in remission.

\section{Discussion}

The present case confirms the effectiveness of $10 \mathrm{mg}$ prednisone orally once daily to cure an incipient insulininduced LIL, localized at a Humalog ${ }^{\mathrm{TM}}$ infusion site, under conditions of ongoing subcutaneous Humalog ${ }^{\mathrm{TM}}$ application elsewhere at the abdomen. In contrast to a previous LIL episode in the same patient [5], prednisone treatment was required for only five months altogether, most likely because it was started early after the onset of the LIL when the defect was relatively small. The first episode of LIL had produced lipoatrophic defects which were more than twice as large $(6 \times 7 \mathrm{~cm})$ as the present one. They had existed already for up to 11 months before treatment was initiated and, hence, required prednisone for 10 months for complete resolution.

The etiopathogenesis of insulin-induced LIL is unknown. In our case, the mechanical needle trauma or the injected agent (Humalog ${ }^{\mathrm{Tm}}$ ) potentially could have played a role, as both had been continued since the first LIL episode. The importance of the injected agent is emphasized by a previous placebo-controlled study of pegylated growth hormone [9]. While 13 percent of patients injecting pegylated growth hormone developed LIL, none of the patients injecting a placebo (containing the same components as the verum, except for the pegylated growth hormone, that is water, sodium phosphate, mannitol and glycine) did. The LIL resolved spontaneously within two to three months after cessation of the growth hormone preparation [9]. Likewise, insulin-induced LIL in a type- 2 diabetic patient resolved spontaneously within six months after cessation of any insulin treatment [10].

In our patient it was not possible to stop the administration of insulin by subcutaneous route. Changing the insulin brand had proved ineffective previously [5]. Hence, we resorted to drug treatment by oral prednisone, as in the first LIL episode two years ago [5]. The effective dose was $10 \mathrm{mg}$ daily; $5 \mathrm{mg}$ /day was presumably not enough (see Figures 1, 2). Glucocorticoids have proved effective in other cases of incipient insulin-induced LIL [5,11-13]; however, the pathophysiological basis of the effectiveness remains to be determined. Is it the anti-inflammatory effect [14]? In our case, the incipient LIL did not appear inflamed (see Figures 1, 2). Is it the corticoid effect on fat cell differentiation? Hauner et al. [15] have demonstrated in vitro that glucocorticosteroids and insulin stimulate the differentiation of adipocytes from preadipocytes and their enlarging.

Similar to the first episode of LIL, which was preceded by a hepatitis vaccination, the second one was also preceded by an affection of the immune system, as evidenced by a herpes zoster rash four weeks before. Parallels may be drawn to infectious mononucleosis, an infection by another herpes virus (Epstein-Barr virus), which triggers an

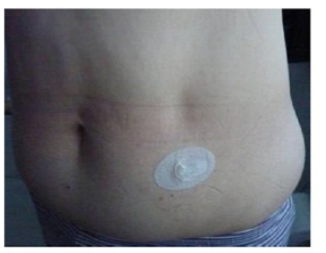

2.12.2012

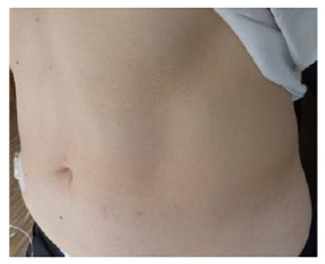

24.3.2013

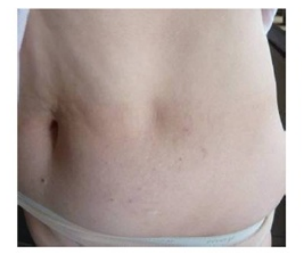

3.1 .2013

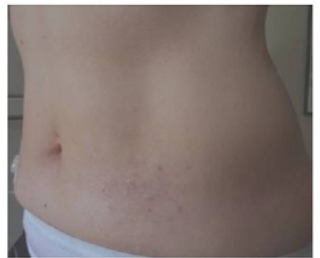

14.4.2013

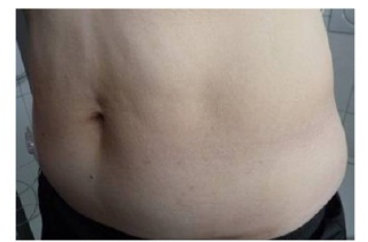

3.2 .2013

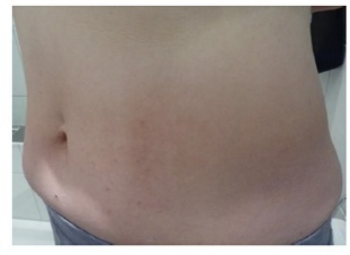

7.12 .2013

Figure 2 Development of localized involutional lipoatrophy at the insulin infusion site, before (2 December 2012 ) and after resumption of 10mg prednisone daily (the end of December 2012 to mid-March 2013, tapered off until 24 March 2013 ). No prednisone from 25 March 2013 until 31 December 2013. 
adverse drug reaction (exanthema) to ampicilline in susceptible patients $[16,17]$. Unfortunately, previous reports on insulin-induced LIL have never considered the possibility that certain intercurrent illnesses or disturbances of the immune system may have instigated the onset of the condition.

The signal for the drug reaction (fat tissue involution) in our case most likely originated from an interaction of the subcutaneously administered insulin lispro with some unknown transient immunologic (or other) idiosyncratic trigger. Idiosyncrasy, however, implies individual susceptibility [18]. Consistent with this theory, four other insulin-treated diabetic patients with herpes zoster, two of whom with significant thyroid autoimmunity [19], never exhibited LIL (see Table 1). They probably lack the specific susceptibility (E.A.C., unpublished).

Various subcutaneously administered pharmaceuticals including hormone preparations [1-6,8-13,20,21] and vaccines [22] may be the cause of LIL. In cases of incipient insulin-induced LIL, the idiosyncratic trigger can obviously be turned off by systemic corticosteroid application, despite ongoing subcutaneous insulin administration. Moreover, corticosteroid treatment may help the atrophied fat tissue to regenerate. It remains to be demonstrated if corticosteroids are of similar effectiveness in other phases and types of LIL.

\section{Conclusions}

The present case demonstrates the favorable outcome of insulin lispro (Humalog ${ }^{\mathrm{Tm}}$ ) associated localized involutional

\begin{tabular}{|c|c|c|c|c|}
\hline \multicolumn{5}{|c|}{ Zoster patients without insulin-induced LIL } \\
\hline Gender & male & female & male & female \\
\hline Age, years & 56 & 60 & 59 & 79 \\
\hline Type of diabetes & type-1 & type-1 & type-1 & type-2 \\
\hline Duration of diabetes, years & 37 & 36 & 28 & 19 \\
\hline Diabetic complications ${ }^{1}$ & none & none & none & none \\
\hline Insulin therapy & injections & injections & $\mathrm{CSII}^{2}$ & injections \\
\hline Application of Humalog ${ }^{T M}$ & no & no & no & no \\
\hline Varicella-zoster $\operatorname{lgG}, \mathrm{mU} / \mathrm{ml}^{*}$ & 1400 & $>2000$ & 1400 & $>2000$ \\
\hline Varicella-zoster lgM ${ }^{*}$ & negative & negative & negative & negative \\
\hline $\mathrm{HbA} 1 \mathrm{c}, \%$ & 7.6 & 7.1 & 7.1 & 8.9 \\
\hline Postherpetic neuralgia & yes & yes & no & no \\
\hline Other relevant features & yes $^{3}$ & yes $^{4}$ & yes $^{5}$ & yes $^{6}$ \\
\hline
\end{tabular}

${ }^{1}$ Neuropathy, retinopathy, nephropathy; ${ }^{2}$ continuous subcutaneous insulin infusion with external insulin pump; ${ }^{3}$ insulin lipohypertrophy: lipoma with focal fibrosis and amyloid deposition (histologically proven); ${ }^{4}$ thyroid autoantibody positive, ${ }^{5}$ immunogenic thyroid atrophy; ${ }^{6}$ multiple allergies; "ELISA, enzyme-linked immunosorbent assay. CSII, continuous subcutaneous insulin infusion; IgG, immunoglobulin $\mathrm{G}$; IgM, immunoglobulin $\mathrm{M}$; $\mathrm{HbA1C}$, glycated hemoglobin. lipoatrophy (LIL), which was treated early after its inception with low-dose prednisone. Of note, the LIL was a recurrence, and the present and the previous episode had been preceded by acute disturbances of the immune system. These observations lend support to the hypothesis that insulin-induced LIL may be a transitory idiosyncrasy.

\section{Consent}

Written informed consent was obtained from the patient for publication of this case report and any accompanying images. A copy of the written consent is available for review by the Editor-in-Chief of this journal.

\section{Abbreviations}

ANA: antinuclear antibodies; ANCA: antinuclear cytoplasmatic antibodies; C3: complement component 3; CSII: continuous subcutaneous insulin infusion; ELISA: enzyme-linked immunosorbent assay; HbA1c: glycated hemoglobin; HLA: human leukocyte antigen; IgA: immunoglobulin A; IgG: immunoglobulin G; IgM: immunoglobulin M; LIL: localized involutional lipoatrophy; mRNA: messenger ribonucleic acid; VZA: varicella-zoster virus.

\section{Competing interests}

The authors declare that they have no conflict of interests.

\section{Authors' contributions}

EAC conceived the idea, compiled the data and drafted the manuscript. RP and JP contributed patient data and the photographs and co-authored the final version of the manuscript. All authors read and approved the final manuscript.

\section{Author details}

${ }^{1}$ Practice of Endocrinology and Diabetology, PD Dr. Kimmerle, Aachener Strasse 196, 40223 Düsseldorf, Germany. ${ }^{2}$ Cäcilienstr.40, 48431 Rheine, Germany.

Received: 8 January 2014 Accepted: 22 April 2014

Published: 24 June 2014

\section{References}

1. Lopez X, Castells M, Ricker A, Velazquez EF, Mun E, Goldfine AB: Human insulin analog-induced lipoatrophy. Diabetes Care 2008, 31:443-444.

2. Cabrera-Freitag P, Escalada J, Goikoetxea MJ, Laguna S, Sanz ML, Gastaminza G: A severe case of lipoatrophy due to human insulin and insulin analogs in a patient with diabetes: is an immunological mechanism involved? I Investig Allergol Clin Immunol 2011, 21:417-419.

3. Aviles-Izquierdo JA, Longo-Imedio MI, Hernanz-Hermosa JM, Lazaro-Ochaita P: Bilateral localized lipoatrophy secondary to a single intramuscular corticosteroid injection. Dermatol Online J 2006, 12:17.

4. Peteiro-González D, Fernández-Rodríguez B, Cabezas-Agrícola JM, Araújo-Vilar D: Severe localized lipoatrophy related to therapy with insulin analogs in type 1a diabetes mellitus. Diabetes Res Clin Pract 2011, 91:e61-e63.

5. Chantelau EA, Prätor R, Prätor J, Poll LW: Relapsing insulin-induced lipoatrophy, cured by prolonged low-dose oral prednisone: a case report. Diabetol Metab Syndr 2011, 3:33.

6. Milan G, Murano I, Costa S, Pianta A, Tiengo C, Zulato E, Centobene C, Bruttomesso D, Cinti S, Vettor R: Lipoatrophy induced by subcutaneous insulin infusion. Ultrastructural analysis and gene expressing profiling. J Clin Endocrinol Metab 2010, 95:3126-3132.

7. Nagase T, Katsura Y, Iwaki Y, Nemoto K, Sekine H, Miwa K, Oh-I T, Kou K, Iwaya K, Noritake M, Matsuoka T: The insulin ball. Lancet 2009, 373:184.

8. Babiker A, Datta V: Lipoatrophy with insulin analogues in type 1 diabetes. Arch Dis Child 2011, 96:101-102.

9. Touraine P, D'Souza GA, Kourides I, Abs R, Barclay P, Xie R, Pico A, TorresVela E, Ekman B, GH Lipoatrophy Study Group: Lipoatrophy in GH deficient patients treated with a long-acting pegylated GH. Eur J Endocrinol 2009, 161:533-540.

10. Tavare AN, Doolittle HJ, Baburaj R: Case report. Pan-insulin allergy and severe lipoatrophy complicating type-2 diabetes. Diabet Med 2011, 28:500-503. 
11. Whitley TH, Lawrence PA, Smith CL: Amelioration of insulin lipoatrophy by dexamethasone injection. JAMA 1976, 235:839-840.

12. Ramos AJS, Farias MA: Human insulin-induced lipoatrophy. A successful treatment with glucocorticoid. Diabetes Care 2006, 29:926-927.

13. Swelheim HT, Westerlaken C, Van Pinxteren-Nagler E, Bocca G: Lipoatrophy in a girl with type 1 diabetes: beneficial effects of treatment with a glucocorticoid added to an insulin analog. Diabetes Care 2012, 35:e22.

14. Petruschke $\mathrm{T}$, Hauner $\mathrm{H}$ : Tumor necrosis factor alpha prevents the differention of human adipocyte precursor cells and causes delipidation of newly developed fat cells. J Clin Endocrinol Metab 1993, 76:742-747.

15. Hauner H, Entenmann G, Wabitsch M, Gaillard G, Ailhaud G, Negrel R, Pfeiffer EF: Promoting effect of glucocorticoids on the differentiation of human adipocyte precursor cells cultured in a chemically defined medium. J Clin Invest 1989, 84:1663-1670.

16. Levy M: Role of viral infections in the induction of adverse drug reactions. Drug Saf 1997, 16:1-8.

17. Zhang $X$, Liu F, Chen $X$, Zhu X, Uetrecht J: Involvement of the immune system in idiosyncratic drug reactions. Drug Metab Pharmacokinet 2011, 26:47-59.

18. Uetrecht J, Naisbitt DJ: Idiosyncratic adverse drug reactions: current concepts. Pharmacol Rev 2013, 65:779-808.

19. Salgin B, Meissner T, Beyer P, Haberland H, Borkenstein M, Fussenegger J, Brand U, Hauffa BP, Hungele A, Holl RW: Lipoatrophy is associated with an increased risk of Hashimoto's thyroiditis and coeliac disease in female patients with type 1 diabetes. Horm Res Paediatr 2013, 79:368-372.

20. Chakraborty PP, Bhattacharjee R: Injection site lipoatrophy: a rare complication of recombinant human insulin. J Assoc Physicians India 2010, 58:630.

21. Del Olmo Ml, Campos V, Abellán P, Merino-Torres JF, Piñón F: A case of lipoatrophy with insulin detemir. Diabetes Res Clin Pract 2008, 80:e20-e21.

22. Ojaimi S, Buttery JP, Korman TM: Quadrivalent Human Papillomavirus recombinant vaccine associated lipoatrophy. Vaccine 2009, 27:4876-4878.

doi:10.1186/1752-1947-8-223

Cite this article as: Chantelau et al: Insulin-induced localized lipoatrophy preceded by shingles (herpes zoster): a case report. Journal of Medical Case Reports 2014 8:223.

\section{Submit your next manuscript to BioMed Central and take full advantage of:}

- Convenient online submission

- Thorough peer review

- No space constraints or color figure charges

- Immediate publication on acceptance

- Inclusion in PubMed, CAS, Scopus and Google Scholar

- Research which is freely available for redistribution 